\title{
Humic substances: new approaches for their isolation from natural objects
}

Popov A.I. ${ }^{1}$, Simonova J.V. ${ }^{1}$, Tcivka K.I. ${ }^{2}$, Song Ge ${ }^{1}$, Birilko D.A. ${ }^{1}$, Kholostov G.D. $^{1}$, Sazanova E.V. ${ }^{1}$

${ }^{1}$ St. Petersburg State University, St. Petersburg, Russian Federation, paihumic@gmail.com

${ }^{2}$ St. Petersburg State Agrarian University, St. Petersburg, Russian Federation

doi: 10.36291/HIT.2019.popov.044

Organic matter of some natural objects (soils, brown coals, peats, bottom sediments etc.) is a complex of various organic compounds. In addition to humic substances (HS) in its composition includes: lipids (waxes, fats, gums and et al.), pigments (oxyanthraquinones and related substances, tetrapyrole compounds and carotenoids), kerogen, glomalin and so on. In the traditional assessment of qualitative composition of natural object organic matter, all the listed substances, as well as the hydrolytic degradation products of particulate organic matter, pass into the alkaline solution (Figure 1). The resulting mixture, which has both specific and individual organic compounds, is usually separated into fulvic acids, hymatomelanic acids, and humic acids only.

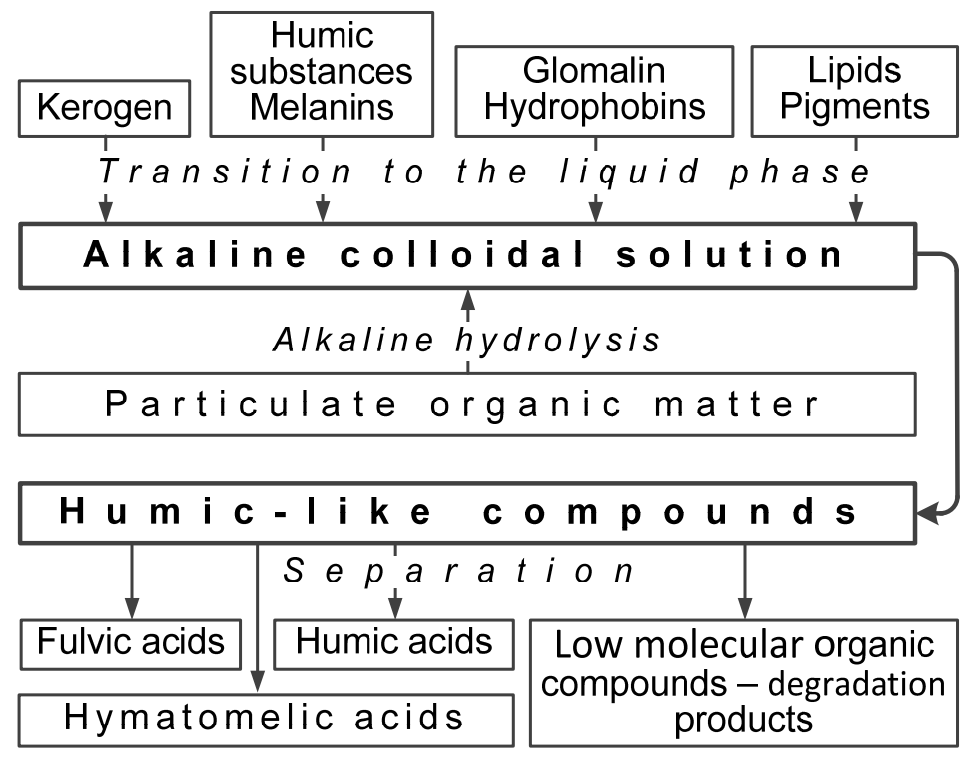

Figure 1. Scheme of humic-like compounds isolation by alkaline solution and their separation.

We propose new approaches to isolate clean HS from natural objects. They includes: (i) preliminary extraction of individual organic compounds, which are soluble in $90 \%$ acetone solution (specifically tetrapyrole compounds and carotenoids); (ii) HS and glomalin isolation by organic solvent after a preceding protonation; (iii) HS separation from glomalin by a certain sorbent; (iv) isolation of water-soluble organic compounds, as well as fresh and semi-decomposed postmortem residues and excreta of plants and soil biota; (v) lipid isolation by benzene-ethanol mixture; (vi) kerogen determination by thermal method (based on of the loss on ignition).

These approaches were experimentally tested on samples of some soils. Note that the biological activity of HS, which were isolated by an organic solvent, was higher activity of HS, which were isolated from same soils by an alkaline sodium pyrophosphate solution.

The authors understand that the new scheme of HS isolation from natural objects is not yet fully worked out, that it is only the first approximation for decision of problems, which are connected with HS chemistry. 